www.nature.com/ejhg

\title{
A cautionary note: false homozygosity for $B R C A 2$ 6174delT mutation resulting from a single nucleotide polymorphism masking the wt allele
}

\author{
Angela R Solano ${ }^{* 1,2}$, Ricardo J Dourisboure ${ }^{1}$, Jeffrey Weitzel ${ }^{3}$ and Ernesto J Podesta ${ }^{2}$ \\ ${ }^{1}$ Laboratory ACDM-Instituto Alexander Fleming, Buenos Aires, Argentina; ${ }^{2}$ Laboratory HRDC-Department of \\ Biochemistry, Faculty of Medicine, University of Buenos Aires, Argentina; ${ }^{3}$ Department of Clinical Cancer Genetics, \\ City of Hope Cancer Center, Duarte, California, USA
}

\begin{abstract}
Sequencing an amplification product of the terminal segment of $B R C A 2$ exon 11 showed apparent homozygosity for the 6174delT mutation in two healthy sisters. Subsequent sequencing of an alternate overlapping amplicon revealed the presence of the $5972 \mathrm{C}>\mathrm{T}$ polymorphism, which is within the standard upstream amplification primer. This mismatch was responsible for the failure to amplify the normal (5972T) allele in both sisters who were heterozygous for the 6174delT mutation. Though the unexpected finding of apparent homozygosity for the 6174delT mutation prompted re-evaluation of the assay, the potential for false negative results due to masking of a mutation-bearing allele by such a circumstance should be a cautionary note for the testing and also in the interpretation of the results published under such assay conditions.
\end{abstract}

European Journal of Human Genetics (2002) 10, 395 - 397. doi:10.1038/sj.ejhg.5200821

Keywords: BRCA2 6174delT; hereditary breast cancer; $B R C A 2$ testing

Genetic testing for germline mutation is one of the benefits of the genetic revolution of the last decade, allowing the detection of individuals at high risk for developing a disease. This information is important in the clinical management of the patient and the family in many instances. ${ }^{1-5}$

One of the most common approaches for the detection of a mutation in the germline is the amplification of the genomic DNA in the region flanking the site to be tested, and direct sequencing of that product. As a rule, both alleles are supposed to be amplified and analysable by sequencing or by other methods. ${ }^{6,7}$

*Correspondence: Dr AR Solano; Departamento de Bioquímica (Lab. HRDC), Facultad de Medicina (UBA), Paraguay 2155 5to. piso, (1121) Buenos Aires, Argentina. Tel/fax: 54 - 11- 45552967;

E-mail: asolano@ciudad.com.ar

Received 21 December 2001; revised 15 April 2002; accepted 16 April 2002
Using standard published primer sequences to test for the BRCA2 6174delT Ashkenazi Jewish founder mutation, ${ }^{7}$ we studied a healthy 54-year-old woman with a family history of cancer on both the maternal and paternal sides of the pedigree (Figure 1). Initial analysis by sequencing an amplification product indicated apparent homozygosity for the 6174delT mutation (Figure 1). Her sister, 56 years old and also healthy, showed the same result. These findings were confirmed by bi-directional sequencing of the amplification products in both cases (not shown).

The presence of polymorphic sites in the genome region where the amplification primers anneal might cause a base pair mismatch and, as a result, a lack of amplification of the allele carrying the polymorphism. The genomic sequences of the regions corresponding to both amplification primers contain a few polymorphic sites as follows: 5965T $>\mathrm{C}$ and, as mentioned, $5972 \mathrm{C}>\mathrm{T}$ for TDSFB and $6283 \mathrm{~T}>\mathrm{C}$ and $6286 \mathrm{G}>\mathrm{A}$ for CGORF-RH. Therefore we searched for the 

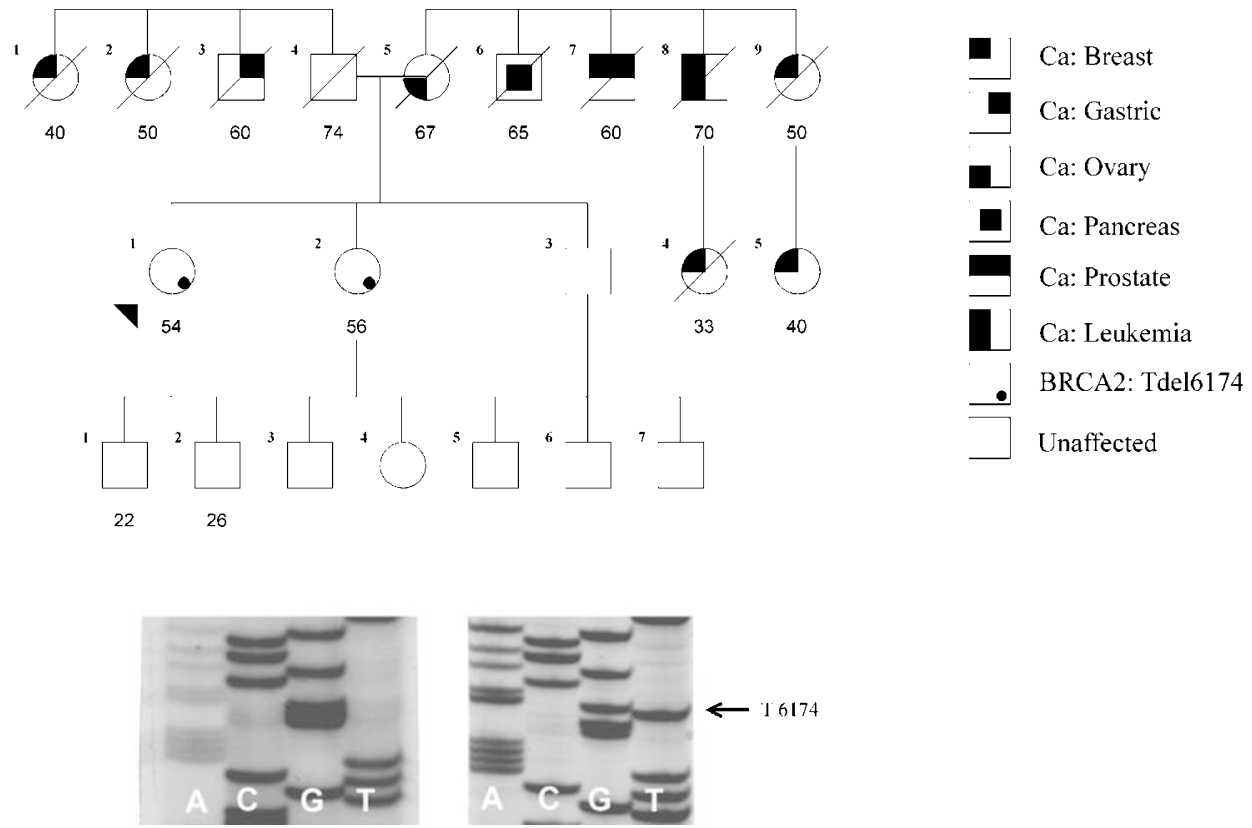

Figure 1 Family kindred with strong history of cancer: the proband is marked with the arrow. Number under the symbol is the age. Gel sequences: compatible with homozygosity for the BRCA2 6174delT mutation (left) and normal sequence with the 6174T marked by the arrow (right)

presence of these polymorphisms in the genomes of both sisters. Primers flanking the original amplified segment were designed to amplify and sequence the region where the former primers anneal. The results showed heterozygosity for the $5972 \mathrm{C}>\mathrm{T}$ polymorphism and also for the BRCA2 6174delT mutation.

The recognition of this technical problem is important. As was discovered here, a false report of homozygosity could be described for the mutated allele using the standard assay. Had the situation been the reverse, the mutation would have been missed, and consequently underestimated their cancer risk. The exceptional nature of this result made possible this report. Similar implications were described in a report of a human BRCA1 knockout caused by mispriming during polymerase chain reaction. ${ }^{8}$

An ancillary observation from this case is the fact that both mutation carriers in this report are healthy in their fifties, prompting speculation about possible epistatic interaction modifying the expression of the abnormal BRCA2 allele. It is unknown whether there is any effect of association of the $5972 \mathrm{~T}$ polymorphism and BRCA2 6174delT in an individual and the absence of disease. We do not know the status of the $5972 \mathrm{~T}$ polymorphism or 6174 delT mutation in the sole living relative that has already developed breast cancer because she lives in another country. Double heterozygotes for $B R C A 1$ plus $B R C A 2$ mutations have been described, ${ }^{9}$ but the phenotype is apparently not worse than for either mutation alone.
The described method ${ }^{7}$ was used to estimate the carrier frequency of the BRCA2 6174delT mutation among Ashkenazy Jewish individuals ${ }^{10}$ and also in many other citations, $^{11-13}$ these valuable initial findings may be different depending on the association in the same allele of the 5972T polymorphism and 6174delT mutation.

In summary, unless heterozygosity is detected, genetic testing results should be carefully reviewed for the potential that one of the alleles is masked. The key point is ensuring the analysis of both alleles to avoid false negative reports. Overlapping amplicons that contain the same mutation may allow the detection of both alleles, as shown in this report. The primers design must take into account for the presence of polymorphic sites in the genome sequence, and still be alert of a difficult problem to circumvent as long as a complete catalogue of the genetic variation in the gene under study is lacking. These concepts should also be taken into account, when population studies are conducted using a unique amplification product as a substrate for sequencing or other techniques like ASO (allele specific oligomerization).

\section{Acknowledgements}

We thank to Dr Brian Ward and Thomas Scholl for their help in the BRCA2 sequence data. This work was supported by CONICET (Consejo Nacional de Investigaciones Científicas y Técnicas) and Universidad de Buenos Aires. 


\section{References}

1 Hartmann LC, Schaid DJ, Woods JE et al: Efficacy of bilateral prophilactic mastectomy in women with a family history of breast cancer. $N$ Eng J Med 1999; 340: $38-44$.

2 Niccoli-Sire P, Murat A, Baudin E et al: Early or prophylactic thyroidectomy in MEN 2/FMTC gene carriers: results in 71 thyroidectomized patients. Eur J Endocrinol 1999; 141: 468-474.

3 Terdiman JP, Conrad PG, Sleisenger MH: Genetic testing in hereditary colorectal cancer: Indications and procedures. Am J Gastroenterol 1999; 94: 2344-2356.

4 Vasen HFA, Watson P, Mecklin J-P, Lynch HT, (ICG-HNPCC): New clinical criteria for hereditary nonpolyposis colorectal cancer (HNPCC, Lynch syndrome) proposed by the international collaborative group on HNPCC. Gastroenterology 1999; 116: 14531456.

5 Salovaara R, Loukola A, Kristo P et al: Population-based molecular detection of hereditary nonpolyposis colorectal cancer. J Clin Oncol 2000; 18: $2193-2200$.

6 FitzGerald MG, MacDonald DJ, Krainer M, Hoover I, O’Neil E, Unsal H: Germ-line BRCA1 mutations in Jewish and non-Jewish women with early-onset breast cancer. $N$ Engl J Med 1996; 334: $143-149$.

7 Neuhausen S, Gilewski T, Norton L et al: Recurrent BRCA2 6174 delT mutations in Ashkenazi Jewish women affected by breast cancer. Nature Genet 1996; 13: 126-128.
8 Kuschel B, Gayther SA, Easton DF, Ponder BAJ, Pharoah PDP: Apparent human BRCA1 knockout caused by mispriming during polymerase chain reaction: Implications for genetic testing. Genes, Chromosomes Cancer 2001; 31: 96-98.

9 Ramus SJ, Friedman LS, Gayther SA, Ponder BAJ: A breast/ovarian cancer patient with germline mutations in both BRCA1, BRCA2. Nature Genet 1997; 15: 14-15.

10 Oddoux C, Struewing JP, Clayton CM et al: The carrier frequency of the BRCA26174delT mutation among Ashkenazy Jewish individuals is approximately 1\%. Nature Genet 1996; 14: 188-190.

11 Beller U, Halle D, Catane R, Kaufman B, Honreich G, Lavy-Lahad E: High frequency of BRCA1 and BRCA2 germline mutations in Ashkenazy Jewish ovarian cancer patients, regardless of family history. Gynecol Oncol 1997; 67: 123-126.

12 Krainer M, Silva-Arrieta S, FitzGerald MG et al: Differential contributions of BRCA1 and BRCA2 to early-onset breast cancer. $N$ Eng $J$ Med 1997; 336: 1416-1421.

13 Robson ME, Offit K: New BRCA2 mutation in Ashkenazy Jewish family with breast and ovarian cancer. Lancet 1997; 350: 117 118. 